\title{
Analisa Perancangan Sistem Informasi Komputerisasi Cuti Pegawai Pada Kantor Kecamatan Majasari Kabupaten Pandeglang
}

\author{
Erni Krisnaningsih ${ }^{1}$, Acang ${ }^{2}$ \\ Program Studi Manajemen Informatika Politeknik Piksi Input Serang \\ Jl. Trip Jamaksari No 6A Ciceri Serang Banten Indonesia \\ Program Studi Manajemen Informatika AMIK Serang \\ Jl. KH. Fatah Hasan No 32 Ciceri Serang Banten Indonesia \\ 'erni_krisnaningsih@yahoo.co.id, \\ ${ }^{2}$ chank_eyek88@yahoo.co.id
}

\begin{abstract}
Kecamatan Majasari terbentuk berdasarkan peraturan daerah Kabupaten Pandeglang nomor 26 tahun 2007 dengan luas wilayah 2.3010,67 Ha. Dan pusat pemerintahan kecamatan, terletak di majasari, sekitar $3 \mathrm{~km}$ dari pusat pemerintahan kabupaten pandeglang. jumlah penduduk kecamtan majasari berdasarkan data bulan desember 2009 dengan jumlah penduduk sebanyak 42.964 jiwa,terdiri dari 22.235 jiwa laki-laki dan 20.729 jiwa perempuan. Kantor kecamatan majasari dapat di jabarkan kondisi pegawai sebagai berikut: Jumlah personil PNS :1orang golongan III/a, 1 orang golongan II/b, 1 orang golongan II/a.CPNS :2 orang golongan III/a, 3 orang golongan II/a. TKK: 9 orang,dan TKS 11 orang.Sehingga total setap pelaksana berjumlah 28 orang pegawai.Pada saat ini Yang berada pada bagian sistem informasi cuti peagawai yang dimilki kantor kecamatan majasari saat ini masih memiliki kendala, terutama dalam sistem informasi cuti pegawai yang masih menggunakan semi komputer, yaitu memasukan data cuti pegawai dengan cara memasukan ke dalam sebuah file atau lembar persyaratan pengajuan cuti pegawai selain itu data yang sudah ada kadang rusak atau hilang, sehingga memerlukan waktu, dan dapat memeperlambat pembuatan laporan cuti. Berdasarkan permasalahan tersebut maka penulis menganggap sangat perlu untuk dirancang sebuah sistem informasi komputerisasi cuti pegawai dengan mengunakan program Delphi7 yang berbasis Database.
\end{abstract}

Kata Kunci : Kecamatan, Kabupaten, Cuti Pegawai, File, Sistem Informasi Komputerisasi

\section{PENDAHULUAN}

Dalam meningkatkan pelayanan dan melaksanakan ketentuan pasal 146 peraturan daerah kabupaten pandeglang Nomor 6 Tahun 2008 tentang pembentukan, Susunan Kecamatan majasari terbentuk berdasarkan peraturan daerah kabupaten pandeglang.

Kantor kecamatan masih memiliki kendala, terutama dalam sistem informasi cuti pegawai yang masih menggunakan cara yang kurang efektif yaitu memasukan data pegawai dengan cara memasukan data ke dalam sebuah file atau lembar persyaratan pengajuan cuti pegawai selain itu data yang sudah ada kadang rusak atau hilang sehingga dalam pembuata laporan membutuhkan waktu.

Berdasarkan permasalahan tersebut di atas maka penulis menganggap sangat perlu untuk dirancang sebuah sistem informasi komputerisasi cuti pegawai dengan mengunakan program Delphi7 yang berbasis Database agar pengolahan atau input data lebih cepat dan akurat baik dalam pencarian data, pemerosesan data serta menyimpan data.

Permasalahan yang ada dalam kantor Kecamatan Majasari yang dihadapi oleh bagian kepegawaian dalam peroses pengajuan cuti pada kantor Kecamatan Majasai sering kali dapat menghambat dalam pembuatan laporan di antaranya :

1) Sistem informasi cuti pegawai masih menggunakan semi komputerisasi sehingga sering terjadi keterlambatan dalam pembuatan surat-surat dan laporan.

2) Sering terjadi kesalahan penginputan data atau salah. Sehingga dalam pengajuan cuti membutuhkan waktu yang lama, karena masih semi komputer.

Tujuan yang ingin dicapai dalam penelitian ini adalah untuk mengkaji dokumen serta menemukan permasalahan yang ada sehingga bisa menemukan solusi yang terbaik dari beberapa permasalahan yang ada.

Mengingat permasalahan yang ada di dalam kantor Kecamtan Majasari khususnya pada dinas kepepegawaian yaitu dalam pengajuan cuti, maka penelitian hanya akan menitik beratkan pada rancangan pelaksanaan pengajuan cuti kerja yang mulai dari analisa masukan, rancangan keluaran sampai dalam pembuatan progaram .

Sistem informasi pengajuan cuti kerja masih menggunakan cara yang semi komputer sehingga kurang efektif karena masih sering terjadi keterlambatan dalam pembuatan surat 
ijin cuti dan laporan. Disamping itu juga sering terjadi kesalahan penginputan data karena tingkat ketelitian operator yang masih kurang sehingga mengakibatkan peroses pengajuan cuti kurang epektif, dan tepat waktu.

\section{METODOLOGI PENELITIAN}

Teknik-teknik yang penulis pergunakan dalam pengumpulan data pada objek penelitian, sebagai berikut :

a) Penelitian kepustakaan ( Library Reseacrh ) yaitu mencari data dari buku-buku dan dokumen yang ada serta relevasinya dengan pembahasan Materi Seminar ini .

b) Observasi yaitu Melakukan penelitian secara langsung proses pengawasan dibagian kepegawaian kantor kecamatan majasari pandeglang.

c) Wawancara (Interview) yaitu Dengan cara mengajukan tanya jawab secara langsung dengan beberapa pegawai di bagian kepegawaian.

\section{HASIL DAN PEMBAHASAN}

Perancangan sistem di buat untuk mengoptimalkan sistem yang sedang berjalan, sehingga Sistem Pengolahan Data Cuti Pegawai dapat di lakukan dengan lebih cepat, akuran, mudah dan efisien.

Dalam rancangan sistem yang di usulkan ini akan di bahas antara lain mulai dari Rancangan Basi Data, yang terdiri dari Entity Relationship Diagram (ERD) , Transformasi ERD ke logical Record Structure (LRS) dan Transformasi LRS ke Relasi / Tabel , serta Normalisasi . Disamping itu juga akan di buat Rancangan Diagram Arus Data (DAD) yang di usulkan, Spesifikasi Proses, Spesifikasi Basis Data, bagian Terstruktur, Rancangan keluaran, Rancangan Masukan Rancangan Waktu, Rancangan Tenaga Kerja Dan rancangan Biaya.

Rancangan Basis Data pada Sistem Pengolahan Data Cuti Pegawai yang di usulkan akan selain membuat Entity Relatinship Diagram (Diagram hubungan antara entitas ), Logical Record Structure (Struktur Data Logika) dan Tabel, juga akan di buat normalisasi data yang berpungsi untuk menghilangkan data yang rangkap.

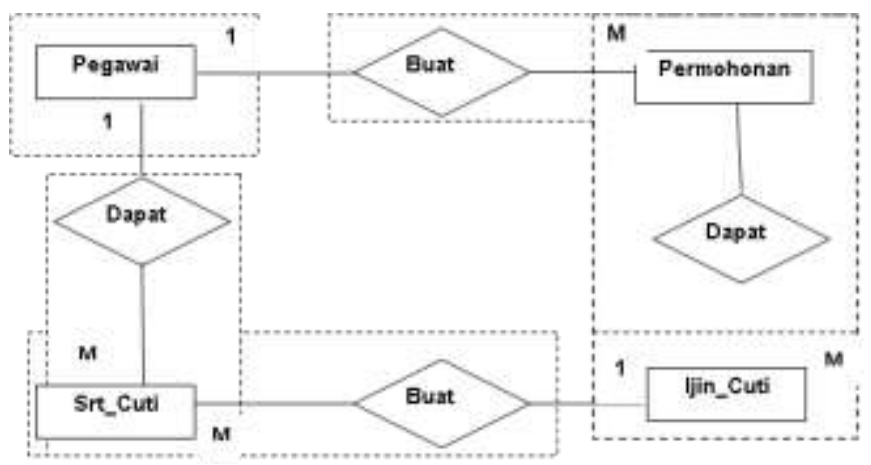

Gambar 1 Transformasi Entityset Relationship Diagram (ERD) Ke Logical Record Structure (LRS)

\begin{tabular}{|c|c|}
\hline PEGAWA & PERMOHONAN \\
\hline $\begin{array}{l}\text { NIP(PK) } \\
\text { Nama } \\
\text { Jabatan } \\
\text { Bagian } \\
\text { Golongan } \\
\text { Pangkat }\end{array}$ & $\begin{array}{l}\text { No Permohonan(PK) } \\
\text { Tgl_Cuti } \\
\text { Jns_Cuti } \\
\text { Mulai_Cuti } \\
\text { Lama_Cuti } \\
\text { Selesai_Cuti }\end{array}$ \\
\hline Surat Cuti & \\
\hline \multirow{3}{*}{$\begin{array}{l}\text { No Srt Cuti } \\
\text { Tgl_Srt Cuti } \\
\text { Nama } \\
\text { Jabatan } \\
\text { Bagian } \\
\text { Golongan } \\
\text { Mulai_Cuti } \\
\text { Selesai_Cuti } \\
\text { Alamat } \\
\text { NIP(FK) }\end{array}$} & liin Cuti \\
\hline & $\begin{array}{l}\text { Kd ljin Cuti(PK) } \\
\text { Jns_Cuti } \\
\text { Lama_Cuti } \\
\text { No Permohonan(FK) } \\
\text { Kd_ljin_Cuti(PK) }\end{array}$ \\
\hline & \\
\hline Kd liin Cuti & \\
\hline
\end{tabular}

Gambar 2 Logical Record Structure

\section{Rancangan Diagram Arus Data (DAD)}

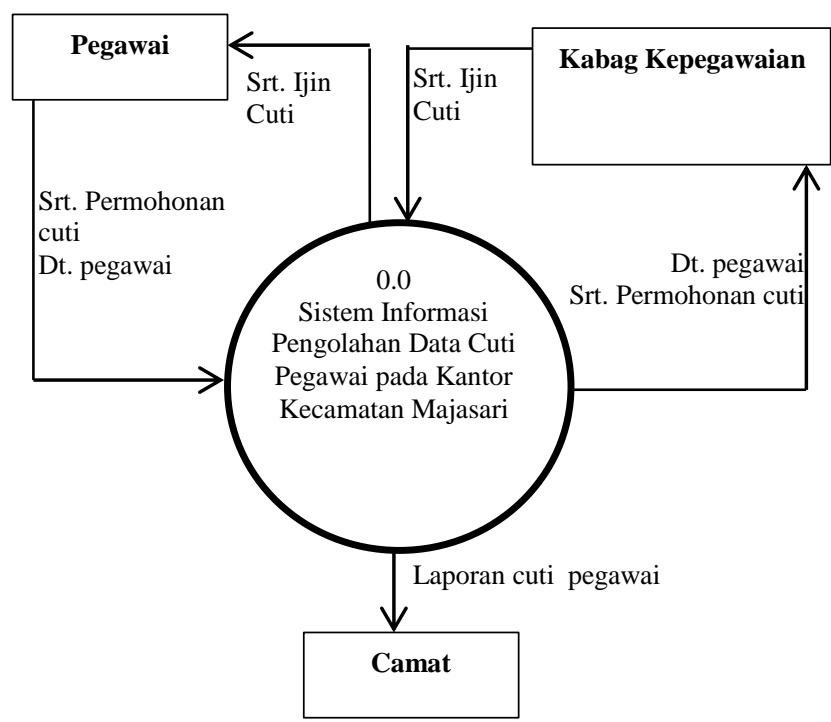

Gambar 3 Diagram Konteks Sistem Informasi Pengoahan Data Cuti Pegawai pada Kantor Kecamatan Majasari

\section{Bagan Terstruktur}

Bagan terstruktur di buat berdasrkan diagram arus data rancangan atau usulan yang telah di buat sebelumnya.

Bagan Terstruktur di gunakan untuk menunjukan : 
1) Ilustrasi organisasi dan Informasi secara berjenjang dalam bentuk modul dan sub modul.
2) Penjelasan lengkap dari sistem tentang hubungan elemen data, elemen control dan hubungan antara modulnya.

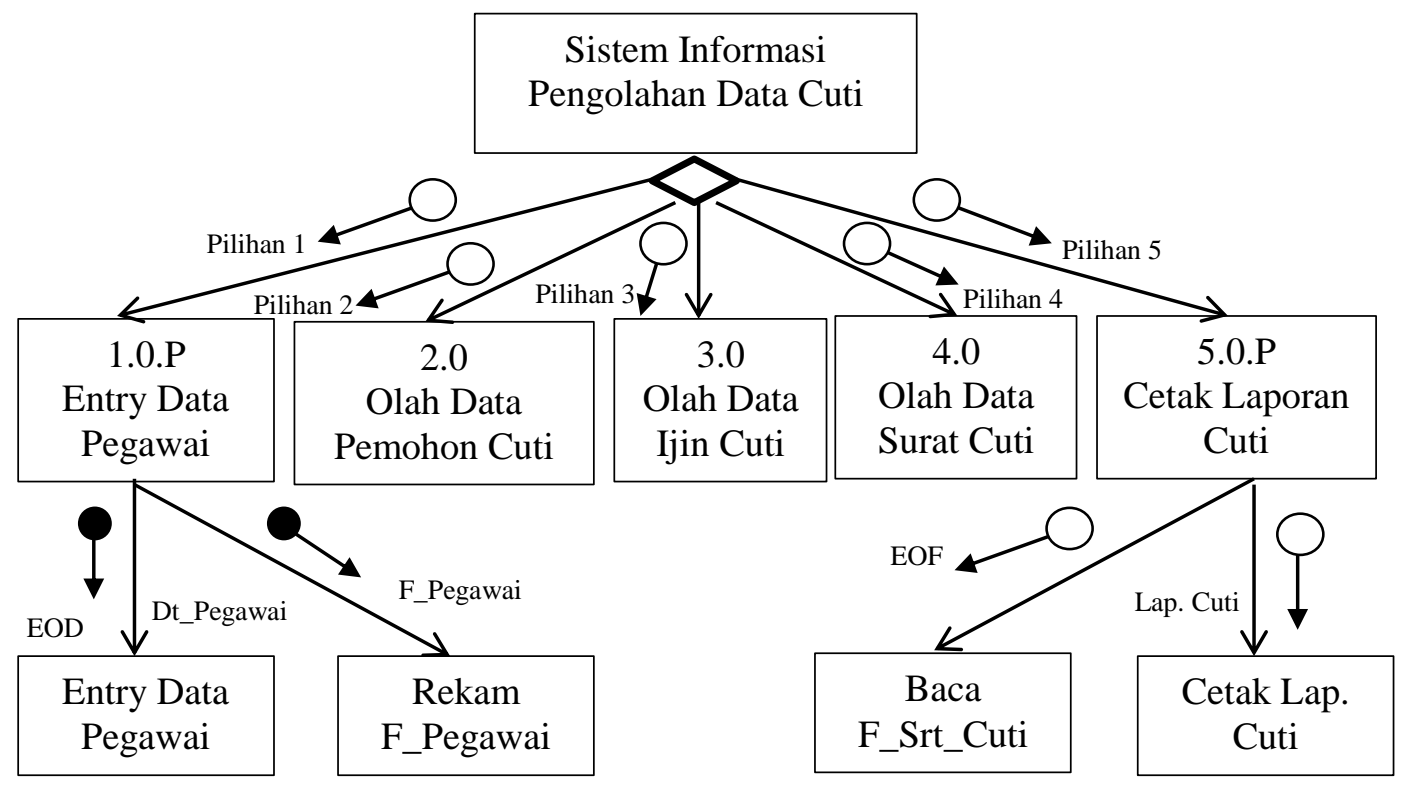

Gambar 4 Bagan terstruktur Sistem Pengolahan Informasi Data Cuti

\section{Rancangan Tampilan}

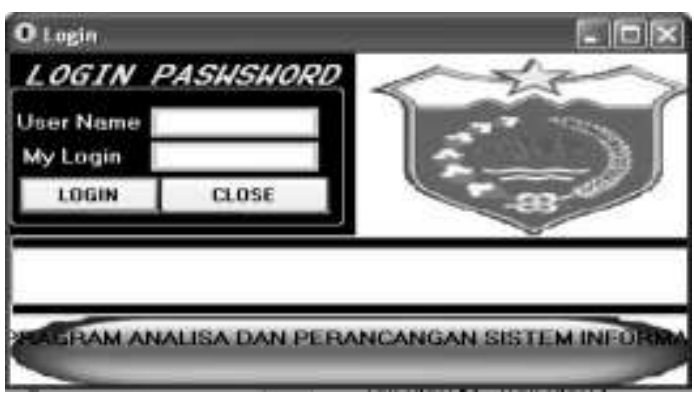

Gambar 5 Form Login

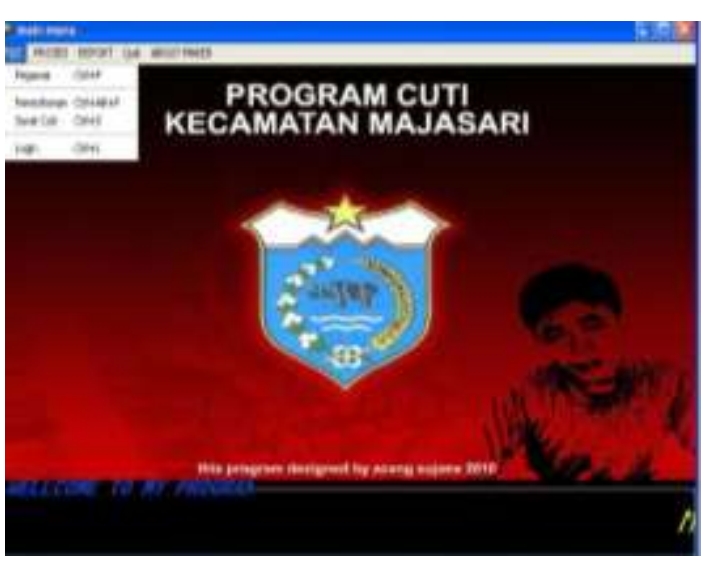

Gambar 6 Form Menu Utama

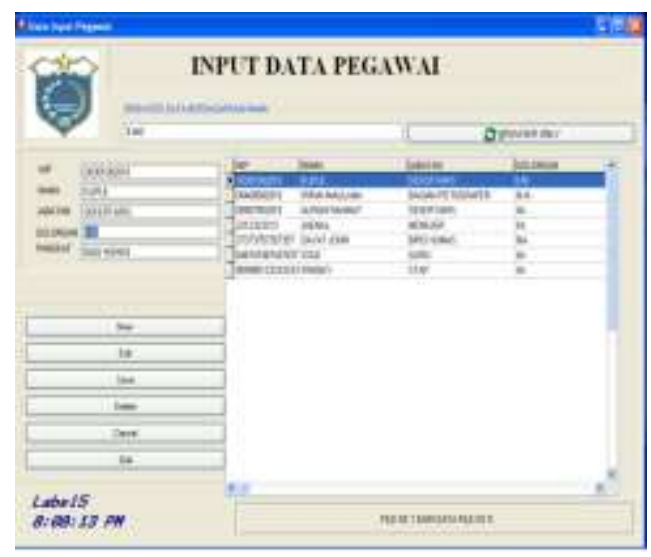

Gambar 7 Form Data Pegawai kantor kecamatan majasari 


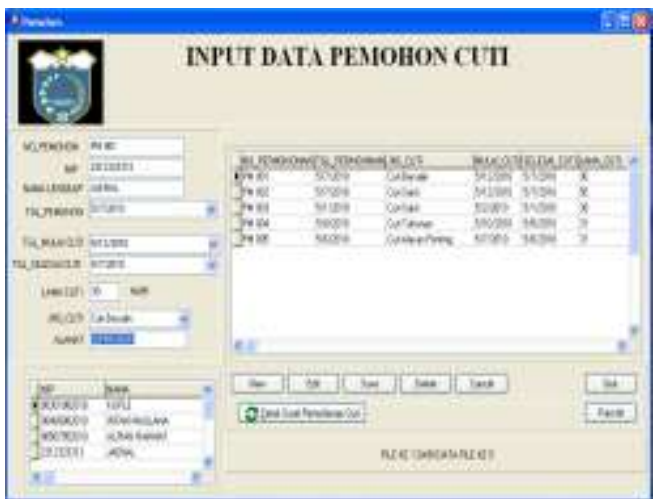

Gambar 8 Form Permohonan Cuti Pegawai kantor kecamtan Majasari

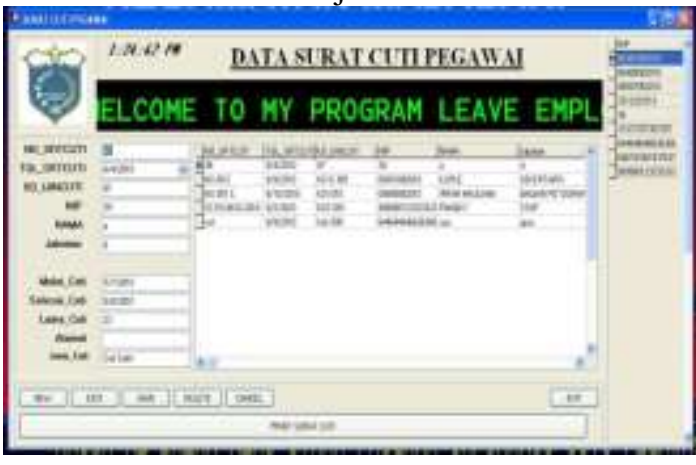

Gambar 9 Form Data surat cuti

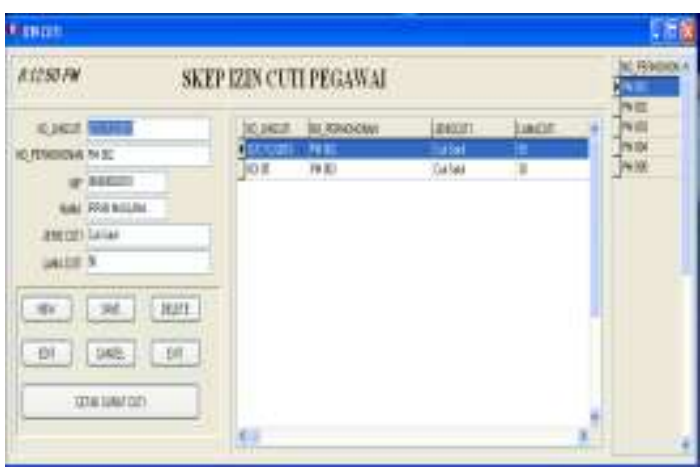

Gambar 10 Form Ijin Cuti

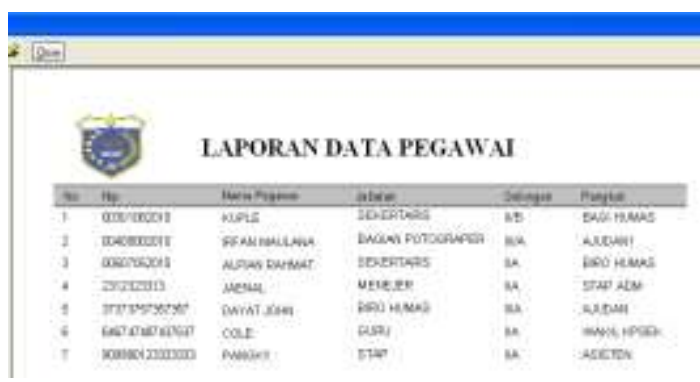

Gambar 11 Laporan Data Pegawai

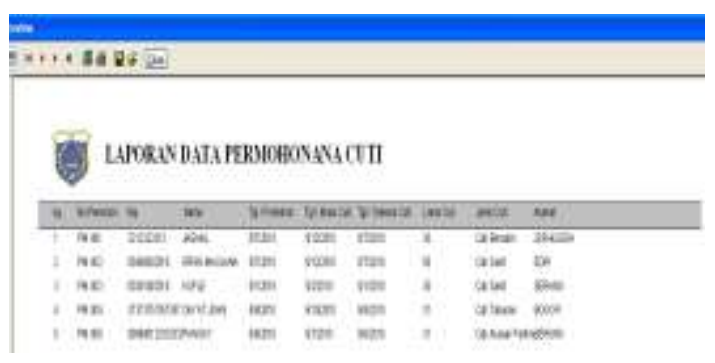

Gambar 12 Laporan Data Permohonan cuti

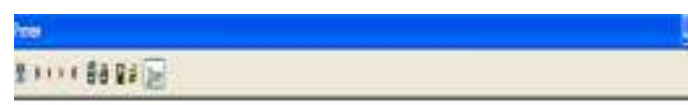

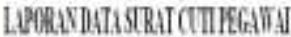

\begin{tabular}{|c|c|c|c|c|c|c|c|c|c|c|}
\hline 1 & aleil: & yex: & apes & is & sa & $w a$ & ind & mid & serie & $\mathrm{hri}$ \\
\hline t & Ea & 到 & kit & mexios & SETE & 樯 & 1 & thes & 50 & का \\
\hline 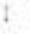 & Eat & iat & or & 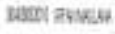 & tasent= & $2 x$ & $i$ & teint & श्या & 20 \\
\hline 1 & EB:A: & int & $\alpha i$ & rentrave & 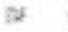 & $=1$ & 1 & Giliater & 秘 & Z\$iा \\
\hline
\end{tabular}

Gambar 13 Laporan Data Surat Cuti Pegawai

\section{Kesimpulan}

Berdasarkan uraian pembahasan yang telah disajikan oleh penulis, maka penulis pada bab-bab sebelumnya, mengambil kesimpulan yang dapat membantu sistem cuti pegawai pada kantor kecamatan majasari kabupaten pandeglang yaitu sebagai berikut :

a. Dalam sistem yang sedang berjalan proses pembuatan surat permohonan dan pelaksanaan cuti pegawai membutuhkan waktu yang cukup lama.

b. Kesalahan - kesalahan yang timbul karena dalam pengelolaannya masih kurang epektif sehingga menimbulkan keterlambatan dalam pembuatan laporan cuti pegawai, dari mulai pormulir cuti pegawai sampai dengan proses pengolahan data cuti pegawai sehingga banyak yang kurang puas dari pihak pegawai.

Referensi

[1] Gordon b Davis, Kerangka Dasar Informasi Manajemen, Edisi IV, IPPM, Jakarta, 1987, Hal 28-29

[2] Jerry FitzGerald. Arda F.FitzGerald. Warren D. Stalling. Jr.Fundamentals Of System Analysis, Edisi ke Dua, New York \& Sons 1981 
[3] Jogiyanto HM, Analisis \& Disain Sistem Informasi Pendekatan Terstruktur Teori dan Praktek Aplikasi Bisnis, Edisi Pertama: Andi Offset,Yogyakarta,1990, Halaman 2
[4] Robert A. Leitch dan K. Roscoe Davis.Accounting Information Systems, (New Jersey Prentice-Hall 1983). Hal. 6 